\title{
Somali refugees' wellbeing: the role of socio-culturally mediated agency
}

\author{
Moses Senkosi Balyejjusa ${ }^{1}$ *
}

(C) Uganda Martyrs University

\begin{abstract}
Although there is substantial research on refugees and their wellbeing, there is limited research that examines the role of refugees' agency in their lives. Using Doyal and Gough's (1991) theory of human need, the study analyses Somali refugees' wellbeing by examining the satisfaction of their human needs. Drawing on data from 70 Somali refugees in Kisenyi, Kampala, the study found that Somali refugees exercised their socio-culturally mediated agency to promote their wellbeing. The socioculturally mediated agency was demonstrated in form of an individual's/family's ability to start and maintain small and medium-scale business enterprises, and develop social networks with the host community, fellow Somalis within Uganda and abroad. Individuals/families that engaged in either or both of the agency actions were able to adequately meet their human needs, thus promoting their wellbeing because adequate satisfaction of human needs leads to human wellbeing.
\end{abstract}

Key Words $\cdot$ Human wellbeing $\cdot$ Human needs $\cdot$ Agency $\cdot$ Somali refugees $\cdot$ Refugees' wellbeing

\section{Introduction}

Wellbeing achievement is one of human beings' life goals, refugees included (Sen, 1985; 2008). Therefore, a lot of research has been carried out, not only on human beings' wellbeing generally, but also on the refugees'. Research on refugee wellbeing has focused on both its objective and subjective aspects. This research has also investigated their psychological wellbeing, mental and acculturation stress. This is mainly because refugees undergo traumatic experiences before, during and after migration (Cheah et al., 2010; Connor, 2010; Potocky-Tripodi, 2003; Takeda, 2000). These experiences lead to psychological and mental problems, thus affecting their psychological and mental wellness. Although there is a lot of research on refugees' wellbeing, it has hardly considered the agency of refugees in the promotion of their wellbeing. Because of the traumatic experiences that refugees go through, they are a vulnerable group (Berry, 2006; Black, 1994; Clark, 2007; Gateley, 2015; O’Higgins, 2012; Schatz, 2009). They are usually considered as passive recipients of aid and support that promotes their wellbeing (Essed, Frerks and Schrijvers 2005; Gateley,

\footnotetext{
${ }^{1}$ Uganda Christian University, *senkosi.moses.b@gmail.com
} 
2015). They are perceived as always in need of help and assistance in order to guarantee their wellbeing.

Although refugees are perceived this way, adopting Doyal and Gough's (1991) theory of human need ${ }^{2}$ as a framework, this study shows that Somali refugees exercised their socio-culturally mediated agency while promoting their wellbeing, by promoting the satisfaction of their human needs. They engaged in actions that were means to achieving and promoting their wellbeing, as individuals, groups and a community. Somali refugees in Kisenyi (a slum in Kampala, Uganda) engaged in starting and running small and medium-scale business enterprises. These enterprises provided employment and financial resources to secure or meet other needs such as housing, food, health care and education. They also engaged in developing and maintaining social networks with Ugandans and fellow Somalis within Kisenyi and abroad. These social networks provided them with significant relationships and financial resources to meet other needs, as is the case with business enterprises. This was mainly through residential concentration ${ }^{3}$. It is the mobilised financial resources from some of the social networks that were used to start some of the business enterprises.

The article starts with a brief discussion of the concept of agency, where the meaning and nature of agency are discussed. The paper argues that agency can be a means or an end in itself. This is followed by a section on the methodology, which focuses on data collection. The next section is a presentation and discussion of the study findings. Demonstrated here is that Somali refugees mainly deployed their socio-culturally mediated agency as a means to promote their wellbeing by promoting adequate satisfaction of their human needs. The two main ways in which Somali refugees demonstrated their socio-culturally mediated agency are analysed. Furthermore, the ways in which each of the socio-culturally mediated agency actions contributed to the wellbeing of Somali refugees are highlighted. Presented thereafter, is the conclusion showing that if refugees are to engage in actions promoting their wellbeing, concerned organisations and institutions should engage in creating agencyconductive environment.

\section{Somali refugees' agency}

The concept of agency has multiple meanings in both academic and everyday usage (Ahearn, 2000; 2001; Asad, 2000; Madhok, 2013; Ortner, 2006). This is because, as Ortner (2001) argues, agency has many dimensions. Accordingly, Ahearn (2001), Giddens $(1984 ; 1993)$ and Ortner $(2001 ; 2006)$ argue that agency has double-pronged: the agency of intention and the agency of power. However, Giddens (1984:9) seems to put more emphasis on the agency of power when he argues, 'agency refers not to the

\footnotetext{
${ }^{2} \mathrm{~A}$ description of this theory is provided for in the presentation and discussion of the findings section.

${ }^{3}$ For purposes of this study, residential concentration is defined as a situation whereby members of an ethnic community/group reside/live in the same residential area.
} 
intentions people have in doing things but to their capability of doing those things in the first place (which is why agency implies power).' Indeed, Karp (1986: 137) shares a similar understanding of agency with Giddens when he observes that agency is about 'causal power'. Although Giddens and Karp tend to emphasise the power attribute of agency, Ahearn (2001) and Ortner (2006) note that the two types of agency (power and intentions) are inseparable. In this paper, therefore, agency is used to mean the conscious intentions and power to act on the intentions (Duranti, 2004; Ortner, 2001; 2006).

Somali refugees' agency has two elements, that is, power and intentions. This is similar to Ahearn (2001), Duranti (2004) and Ortner's (2001; 2006) argument about what constitutes human agency. As it will be shown later, whatever action Somali refugees engaged in was intentional. They had the intention and exercised power in pursuance of the intention. Most Somali refugees' intention to migrate to Kisenyi is to have a good life $e^{4}$. Because of this intention, they exercised their power by migrating to Kisenyi. For instance, Musa (not real name) in an individual in-depth interview observes,

\begin{abstract}
The people (Somali refugees) who are in the camp (Nakivale refugee settlement) are more than those who live in towns like Kampala. The reason why most Somali refugees come here in Kampala is that life in Nakivale (refugee settlement in South Western Uganda) is not good. For instance, there is no good education, health and clean water. The food is not enough. Therefore, Somali refugees come here to start businesses and work so that they can have good life.
\end{abstract}

Although agency has two elements (power and intentions), in this paper agency refers to socio-culturally mediated capability to do things or carry out an action, that is, to act on the intentions (Ahearn, 2001; Essed, Frerks and Schrijvers, 2005; Madhok, 2013; Ortner, 2006; Wertsch, Tulviste and Hagstrom, 1993). As indicated from the outset of this paper and as will later be further demonstrated, Somali refugees' wellbeing is influenced by contextual factors. These contextual factors make Somali refugees' agency socio-culturally constructed, mediated and regulated. Somali refugees' choices, intentions, actions, desires, goals and projects in relation to their wellbeing are socio-culturally constructed, maintained and pursued. Indeed, this argument is similar to Desjarlais' (1997: 205) observations on agency in a shelter for the homeless. He argues, 'in the shelter at least, agency was context-dependent, if we take context to mean both a specific "place" and social, political, and cultural dynamics that give rise to that place.'

Therefore, this paper focuses on socio-culturally mediated intentions and power of Somali refugees in pursuance of their wellbeing. From the definition adopted for this

\footnotetext{
${ }^{4}$ The author defines a good life to Somali refugees as having the ability to satisfy adequately one's human needs
} 
paper, it is clear that agency does not mean free agency or autonomous agency. Free or autonomous agency means free will in the course of acting or acting without any interference (Ahearn, 2000; 2001; Lalu, 2000; Madhok, 2013; Mayr, 2011; Ortner, 2001; 2006). The influence of the socio-cultural factors, similar to Somali refugees, limits an individual's autonomy or free will in relation to intentions and power. The intentions and power are conceived, exercised or deployed within an individual's socio-cultural environment. Indeed, historian Lalu (2000: 49-50) in his critique of autonomous agency observes that 'agency is conditioned by the norms, practices, institutions, and discourses through which it is made available.' Furthermore, Madhok (2013: 7) argues that 'agents exercise agency within particular social contexts, which in turn influences the mode, site and practice of their agency.' In summary, individuals' intentions and power do not exist prior to their socio-cultural context, but they are derived from it (Desjarlais, 1997; Lalu, 2000; Madhok, 2013).

The implication of looking at agency as socio-culturally mediated is that agency becomes relative since there are different socio-cultural contexts. Therefore, whereas some individuals exercise a high degree of agency, others exercise a minimal one depending on the socio-cultural environments they live in (Sewell, 1992). In the case of Somali refugees, as it will be demonstrated, they exercised a high degree of agency due to the socio-cultural environment they live in. Important to note is that Somali refugees' intentions while exercising their agency were either for instrumental or intrinsic reasons. Exercising agency for instrumental reasons is to do something as a means to achieving some additional good or benefit, while exercising agency for intrinsic reasons is to do something as an end in itself (Alvarez, 2009; McGuire, 2012). However, the two are not necessarily mutually exclusive. In the case of Somali refugees, as it will be shown in the presentation and discussion of findings section, they exercised their agency for mainly instrumental reasons, that is, promotion of their wellbeing.

Doyal and Gough's (1991) theory of human need was adopted as a framework for analysing the role of Somali refugees' socio-culturally mediated agency in their wellbeing. According to Doyal and Gough (1991), human wellbeing is about avoidance of serious objective harm. This harm can only be avoided if two universal human needs, physical health (physical survival and absence of diseases) and individual autonomy (capacity to initiate action through formulations of goals and strategies to achieve them) are adequately met. The two universal human needs are met through adequate satisfaction of the eleven universal intermediate human needs. These include nutritional food and clean water, protective housing, non-hazardous work environment, non-hazardous physical environment, safe birth control and childbearing, appropriate health care, security in childhood, significant primary relationships, physical security, economic security, and appropriate education (Dean, 2010; Gasper, 2005; Doyal and Gough, 1991; Gough, 2000; 2003). The universal intermediate human needs are satisfiers of the universal human basic needs because they share universal satisfier characteristics. Universal satisfier characteristics are 
'those properties of goods, services, activities and relationships which enhance physical health and human autonomy in all cultures' (Doyal and Gough, 1991: 157).

This framework is adopted because it focuses on preconditions for wellbeing and not wellbeing, that is, what must be there or in place in order to guarantee human wellbeing (Alkire, 2002). Furthermore, apart from the framework being universal, it allows local and culturally specific application (Alkire, 2002; 2005; Doyal and Gough, 1991). As earlier noted, according to Doyal and Gough (1991), the satisfiers of the intermediate needs are culturally relative. These reasons make the framework useful for the assessment of the wellbeing of Somali refugees and their role in the promotion of their wellbeing.

\section{Methodology}

This paper utilises data collected for a $\mathrm{PhD}$ project. Fieldwork for this project was carried out between July and December 2013 using qualitative approaches. Data were collected from Somali refugees living in Kisenyi. This is because most Somali refugees in Kampala live in Kisenyi (Omata, 2012). Seventy Somali refugees (14 for in-depth individual interviews and 56 for focus group discussions) were recruited for the study using purposive sampling strategies. The study included participants that were aged between 18 and 60 and who had lived in the area for not less than 2 years. The two residence criteria were to ensure that recently arrived refugees who may still be facing challenges of integration are not recruited. The age bracket ensured that age groups with higher opportunities to exercise their agency are recruited for the study. The seventy participants figure was reached after achieving satiety threshold where no new information was being collected from the participants. The study participants included both women and men.

In-depth individual interviews were carried out at various places in Kisenyi convenient to the study participants. I conducted individual interviews with five female and nine male participants with the assistance of translators ${ }^{5}$. Somali refugee men showed more willingness to participate in the study than women did. Since participation in the study was voluntary, the study recruited more male participants than female participants. Individual in-depth interviews were used as a method of data collection because they give an opportunity to study participants to discuss the study issues in their own words (Boeije, 2010; Braun and Clarke, 2013; Marshall and Rossman, 2006). Therefore, this method appropriately aids the examination of the relationship of the Somali refugees' wellbeing and their socio-culturally mediated agency. This can only be studied by providing the participants opportunities to give their views in their own words.

${ }^{5}$ It is highly likely that some information was lost in course of back and forth translating from English to Somali. 
In addition to the individual interviews, seven FGDs were carried out with Somali refugees. Four of the FGDs were carried out at Kyaggwe Primary School, one from Refugee Hope (NGO serving refugees) and two from a house in Kisenyi. With the exception of the latter that had only male participants, the rest of the FGDs had a combination of both female and male study participants. Each FGD had between seven to nine participants, and on average four to five were women. Although it had originally been planned to have gender segregated FGDs, potential female participants were unwilling to participate in FGDs conducted by a male researcher without male Somali refugees. They claimed that this was for religious reasons. This could have influenced the participants, especially women, providing socially desirable responses or totally avoiding certain responses, since this is a patriarchal society. Like the individual interviews with Somali refugee participants, the FGDs were also carried out with the help of the translators.

Data were collected using a FGD guide, and I moderated the FGDs. FGDs were used as a method of data collection because this study is looking at Somali refugees' wellbeing at a group level, and not at an individual level. The group context, that is, the presence of others, and views of group members have effects on individual participants' views and behaviours (Boeije, 2010; Stewart and Shamdasani, 1990). This results in collection of data, which are not about the experiences and opinions of the individual participants, but the group as generated through the interaction (Green and Hart, 1999; Hennink, Hutter and Bailey, 2011; Morgan, 1997). All the interviews and FGDs were audio recorded with their permission.

Thematic analysis was carried out where themes, subthemes, categories and subcategories were developed. Through comparing the codes for similarities and differences, data were grouped into categories and subcategories. Themes and subthemes were developed by comparing developed categories and subcategories from the data (Boeije, 2010; Glesne, 2011; Strauss and Corbin, 1998). These were developed using the literature review, research questions and the data. NVIvo 9 was used as a data management and organisation tool. The data were exported into the software and the process of highlighting and creating themes and subthemes was carried out.

\section{Presentation and discussion of the findings}

Although Doyal and Gough's (1991) framework lists eleven universal intermediate human needs, this study mainly focuses on seven human needs. These include nutritional food, protective housing, healthcare, appropriate education, work, financial security and significant primary relationships. The assessment of these seven indicated that most Somali refugees were in position to adequately satisfy these needs (Balyejjusa, 2017). However, the satisfaction of these needs was partly due to the socio-culturally mediated agency of Somali refugees. This agency was demonstrated in the Somali refugees' ability to start and maintain small and medium-scale business 
enterprises, and develop social networks with the host community, fellow Somalis within Uganda and abroad. Each of these agency strategies is discussed below. It should be noted here that where the participants' words are quoted, pseudo-names are used for ethical reasons.

\section{Small and medium-scale business enterprises}

Malik et al. (2017) argue that the survival of refugees largely depends on their economic activities and resilience (ability to generate regular income and start businesses). Indeed Somali refugees in Kisenyi were not passive recipients of aid, but actively engaged in starting and maintaining small and medium scale business enterprises. For instance, Ibra (Somali refugee participant) in an individual in-depth interview noted, ' $\ldots$ as I told you, Somalis are very good at starting and running businesses. When we come here, we immediately start businesses. We are very active people; we are creative people.' The businesses included supermarkets, shops, fuel stations and restaurants. However, it should be pointed out that not all Somali refugees had started businesses due to lack of financial resources.

Some Somali refugees are able to start business enterprises due to their entrepreneurial culture in addition to the laws of the host community that allow them a right to engage in commerce and gainful employment (Government of Uganda [GOU], 2006; 2010). The law also grants them freedom to reside in any part of the country. Consequently, some refugees left Nakivale refugee settlement for Kampala where they could start small and medium-scale enterprises. Furthermore, the goodwill of the host community should not be underestimated. The members of the host community were some of the customers to the businesses; they did not shun Somali refugee businesses. It is within this combination of factors that Somali refugees exercised their agency, thus making it socio-culturally mediated. They acted within their culture whereby they did not engage in starting any business that conflicts with their culture. Ethnic Somalis and Somali refugees are predominantly Muslims (Abdullahi, 2001; Langellier, 2008). Indeed, Langellier (2008; 2010) argues that most Somalis conflate Islam with Somali culture, with very few being able to separate the two (Islamic practices and Somali cultural practices). Therefore, they did not, for example, have businesses dealing in pork and alcoholic products. In addition, they acted within the laws of Uganda. According to the Refugee Act, 2006, only refugees are able to live self-reliantly that are allowed to live in urban settings. This is well captured by the assertion of a male participant in one of the FGDs,

Let me tell you one fact, Somali refugees are composed of two groups. Those who are financially well off and those who are not. Those who are well off are the ones living here in Kampala and those who are poor live in Nakivale. The refugees living in Kampala have started businesses where we work. Therefore, we get jobs among ourselves in Kampala. We 
create jobs for poor people (Somali refugees). For instance, some Somali girls cook for Somali students at university campuses.

The action of running businesses ensured that Somali refugees had access to employment. Indeed, employment has further benefits to those employed in relation to their wellbeing. Because of this, Wright (2012) in her research with the Peruvian migrants in London and Madrid calls it a functional need. For example, Divakalala's (2008) wellbeing research in Sri Lanka indicates that the participants valued employment because it ensures financial security. In addition, similar to Sen's (1999) argument that women's earning affords women a voice and agency, Somali refugees' earning and financial security enabled them access other wellbeing requirements such as protective housing, health care, appropriate education and food. For instance, Abdu's comment below demonstrates Somali refugees' socio-culturally mediated agency of starting small and medium-scale businesses and their wellbeing:

We come here because we need a good life. We need our children to go to school and we need to work. In Kampala, we easily get jobs because of the many Somali refugee owned businesses. Actually, we are living well. We use the money to pay bills like house rent. In Nakivale, there is nothing (business enterprises).

Although the small and medium scale business enterprises provided Somali refugees with employment, it is interesting that Somali refugees were only concerned with employment and not non-hazardous employment. Doyal and Gough (1991) argue that it is the non-hazardous work environment, which is the human need. According to Wright (2012), they were not only concerned with employment, but also with not demeaning employment. It seems that the non-hazardous work environment is more of a developed and industrialised world concept. Citizens and residents of these countries have alternative mechanisms to live well without a job, such as social welfare programmes. They also have alternative employment opportunities to choose from. However, Somali refugees in Uganda do not have alternatives in terms of employment since the majority of people in Uganda are engaged in self-employment (Uganda Bureau of Statistics, 2013), and there is a high rate of youth unemployment, standing at 18.4 per cent (Uganda Bureau of Statistics, 2017). In such circumstances, an individual would not be pre-occupied with having non-hazardous employment, but just employment. In addition, a non-hazardous requirement in relation to employment is more likely to apply to formal employment ventures than informal employment, especially if the ventures are small and medium scale, as is the case with those started by Somali refugees. 


\section{Development of social networks}

Apart from the Somali refugees' socio-culturally mediated agency of starting and running small and medium-scale businesses, they are also engaged in developing social networks. The role of these networks in people's lives is widely recognised (Caserta, Punamaki and Pirttil-Backman, 2017; Heaney and Israel, 2002; Lim and Putman, 2010; Pinquart and Sorensen, 2000). Similarly, it is also appreciated in the lives of migrants, refugees included (Awumbila, Teye and Yaro, 2017; Fass et al., 2015; Kivisto and Faist, 2010). Indeed Somali refugees in Kisenyi engaged in socioculturally mediated agency to developed and use social networks in their life. The networks were with both Somali refugees within Uganda and abroad. For example, this is well illustrated by a comment from a female participant in one of the FGDs,

My friends are Somalis. Friendship is very important because it adds something of value. Like now, I am living with my friend and my son lives with another friend of mine. In summary, friendship is very important. All friends of mine are fellow Somalis. You know Somalis are very good people; they help each other. She [one of the FGD members] helps me to solve some of my problems. Even sometimes friends are better than brothers are because I have relatives here, but they do not help me.

Somali refugees are able to form social networks with fellow Somali refugees because they share a cultural and religious origin. Somali refugees can be described as mono-cultural considering that they belong to the Cushitic ethnic group, have Somali as a common language and are predominantly Muslim (Abdullahi, 2001; Lewis, 2008; Samatar, 1993). It is within this socio-cultural setting/framework that they form social networks. Furthermore, Somali refugees also act in the socio-cultural framework of being refugees. They are aware that they have limited resources and they must form social networks in order to promote their wellbeing. However, the socio-cultural framework of Somali refugees is promoted and strengthened by Uganda's refugee legal and policy framework. The law and policy grant refugees freedom to live in any part of Uganda as long they have permission from the Commissioner for refugees. They also grant freedom to refugees to reside in urban settings if they are able to be self-reliant (GOU, 2006).

As such, most Somali refugees, if not all, reside in Kisenyi. Gibson (2001) argues that immigrants and refugees live among co-ethnics to ensure maintenance of the culture of origin. However, for Somali refugees in Kisenyi the residential concentration was for material and social support. This is similar to Al-Sharmani's (2003), Jinnah's (2010) and Sadouni's (2009) research in South Africa and Egypt where immigrants lived in residential concentrations. The social support includes giving money and goods, giving directions to places, helping in searching for houses to rent and establishing social relations. All these are important aspects of Somali 
refugees' wellbeing. The importance of residential concentration and social networking among Somali refugees towards their wellbeing was summarised as follows by a female participant in one of the FGDs,

... For example, when you come from Somalia you need guidance or someone to direct you. You need to go where Somali refugees reside when they come to Uganda. Your fellow Somalis will guide you or help with whatever you need here in Kampala, be it a house to rent or schools/universities to join as students. Whatever kind of help in form of direction, you will get it from Somalis.

The above view resonates with Doyal and Gough (1991), Gough (2000), Lim and Putman (2010) and Pinquart and Sorensen (2000). Similarly, the social networks indeed contributed to Somali refugees' wellbeing. They specifically contributed to meet of the human need of significant primary relationships. Indeed, according to Wright (2010) relatedness was on the psychosocial needs of the Peruvian migrants in London and Madrid. The significant primary relationships offered Somali refugees with friends they could spend time with, as the above quote from the FGD member illustrates. According to Doyal and Gough (1991) and Gough (2000), having significant primary relationships is a prerequisite for avoiding serious objective harm in form of deteriorated physical health and autonomy. Deteriorated physical health and autonomy are indicators of ill-being. Doyal and Gough (1991) argue that isolation or not having friends can lead to mental illnesses such as stress, distress and depression.

The social networks Somali refugees developed with fellow Somali refugees within Kisenyi did not only provide significant primary relationships as one of the requirements for human wellbeing, but also facilitated the satisfaction of other human needs of Somali refugees. From the above quote, it is clear that the social networks contributed to meeting two of Somali refugees' human needs, that is, housing and education. Doyal and Gough (1991) and Gough (2000) list these two needs as intermediate needs to ensure that a human being avoids experiencing harm in relation to his/her physical health and autonomy. Indeed Balyejjusa $(2015 ; 2017)$ reports these two as part of Somali refugees' definition of their wellbeing. Due to the social networks, some Somali refugees were able to have their human need of housing met through pooling house rents. For example, Hamid noted the following about pooling house rents with Somali friends: 'we share the house rent whereby each one will pay like 80,000/= per month.' Furthermore, as earlier noted in the sub-section of small and medium scale businesses, the social networks also resulted in some Somali refugees accessing employment from Somali refugee owned business enterprises, as Abdu's comment above demonstrates.

Additionally, Somali refugees who had social networks with fellow Somalis living abroad were in position to receive financial remittances from those networks. This money did not only meet the need of financial security, but also the costs of food, health care, education and housing. All these are wellbeing needs. In addition, some of 
this money is used to start small and medium scale business enterprises (see Omata, 2012)). For instance, Issa (male Somali refugee in in-depth interview) expressed the following about Somali refugees' wellbeing: 'there are people (Somali refugees) who have no problems of living well; they have good jobs, relatives abroad sending them money or businesses.'

Due to financial remittances from abroad, some of the Somali refugees did not seek employment, since the remittances were regular and adequate to meet their wellbeing needs. This category claimed that the potential employers offered low remunerations, and thus, they did not seek employment. This is well captured by Isma's (male Somali refugee in in-depth individual interview), 'yes, some of us work; some of us we work with Ugandans. However, we have our relatives living in the developed countries like America, Canada and Britain. So we mostly receive money from abroad.'

Unlike research on social networks among migrants that asserts that the networks are usually with one's community of origin, similar to Malik et al's (2017) study on refugees in Pakistan, Somali refugees in Kampala also developed social networks with members of the host community. These social networks were also formed in a sociocultural context. First, Uganda in general and Kampala in particular is a multicultural/ethnic setting (Otiso, 2006). In this setting Ugandans form social networks between different ethnic groups. As such, Somali refugees, although coming from a mono-cultural (predominantly one ethnic group) setting, had to start forming social networks with Ugandans. Furthermore, due to the laws of Uganda that prohibit discrimination based on ethnicity/race, gender and religion (GOU, 1995; 2006), Somali refugees sought social networks with Ugandans because they were not being discriminated against. Somali refugees made social networks mainly with Ugandan Muslims, boda boda ${ }^{6}$ riders and house owners. The Somali refugee youth also developed networks with Ugandan youth. This is demonstrated by a comment from a male Somali refugee from one of the FGDs.

The first thing we do while with Ugandans is that we respect them as our neighbours. We greet them in the morning; ask them about their previous night and health. When we go to the markets, we buy from them and we treat them well because we do not believe that Ugandans are bad people; we actually appreciate the way they behave. Now it is necessary for Somalis to respect and behave well while with Ugandans because your neighbour is Ugandan and the person in the market is Ugandan, the one at the university is Ugandan. Therefore, we have to interact with Ugandans and the sooner we start the better.

The social networks with Ugandans, similar to those with fellow Somali refugees in Kisenyi, were fulfilling the need of significant relationships. For instance, a male youth from one of the FGDs pointed out:

\footnotetext{
${ }^{6} \mathrm{Boda}$ boda is a term in Uganda used to refer to motorcycles that are used for public transport
} 
As youths, we Somalis love football [soccer] so much. So, we sometimes make friends while playing football with Ugandans. We sometimes watch the English premier league soccer games together. If someone supports the same team like you, he becomes your friend; you go out together.

The social networks with Ugandans not only facilitated the satisfaction of the human need of significant primary relationships as the above quote shows, but also were for practical and social support. These networks contributed to Somali refugees' financial security because they were customers to Somali owned businesses. A male Somali refugee participant in one of the FGDs illustrates this,

... Okay we interact with Ugandans. First, we tell and show them the things we believe in. We also try to be friends with Ugandans. We sometimes share gifts and actually to show them that we can have a relationship with them regardless of the race, religion or other backgrounds. This is because previously Ugandan people were normally not interacting with us. They used not to have business deals with us. They would also not borrow money from us. There are many houses owned by Ugandans that are being managed by Somali businesspersons. However, there are also some properties that are owned by Somali refugees. Some Ugandans are working on these properties. We give them jobs; they normally work for us and we pay them salaries. In the end, we benefit from each other.

The above quote primarily shows how Somali refugees' agency is socio-culturally mediated. The social networks with Ugandans were made within the Somali refugees' belief system, that is, Islamic teachings and requirements. In addition, using Mauss' (1970) ideas of gift exchange, Somali refugees make effort to interact with Ugandans because they are aware that their goodwill actions are likely to be reciprocated with actions from Ugandans. Secondly, it also shows how Somali refugees' socio-culturally mediated agency contributed to meeting Somali refugees' wellbeing needs.

\section{Conclusions}

This paper has shown that Somali refugees were not passive when it comes to their wellbeing. They engaged in actions that contributed to meeting their wellbeing and human needs. The human needs include nutritional food, health care, education, significant primary relationships, employment, financial security and housing. Somali refugees primarily pursued the satisfaction of these wellbeing human needs using two strategies, starting and running small and medium-scale businesses and developing social networks with Ugandans in Kisenyi and fellow Somali refugees within Uganda and abroad. These strategies were mainly intended to meet the seven wellbeing human needs. 
These two strategies adopted by Somali refugees as means to meeting their human needs were conceived, adopted and exercised within a socio-culturally mediated environment. They were influenced by the Somali refugees' culture and religion, the status of being refugees, the host community and the refugee legal framework in Uganda. For instance, the refugee legal framework granted refugees many rights, such as the freedom to live in any part of the country, freedom to engage in commerce, freedom to receive financial remittances from abroad, and freedom to reside in urban settings as long as they are able to be self-reliant (GOU, 2006). Furthermore, the host community's non-discriminatory behaviours enabled Somali refugees to engage in developing social networks with them (Mugalu, 2011). All these examples illustrate how Somali refugees' actions were socio-culturally mediated.

The implication of this is that organisations, institutions and agencies engaged in activities and programmes promoting the wellbeing of refugees should focus on the social context in which refugees live. This social context determines whether refugees will be passive, active or exercise low-level agency or high-level agency since agency is context-based. The concerned organisations, institutions and agencies should engage in activities that advocate for laws, policies and cultural practices that permit the exercise of high-level agency. This way, these organisations, institutions and agencies will contribute to creating an environment that is conducive to exercise of high-level agency on the part of refugees. As such, refugees, as seen in the case of Somali refugees, will be able to engage in activities and actions that promote their wellbeing.

\section{References}

Abdullahi, D. M., 2001. Culture and customs of Somalia. London: Greenwood press. ActionAid International Uganda., 2012. Lost opportunity? Gaps in youth policy and programming in Uganda. Kampala: ActionAid International Uganda

Ahearn, M. L., 2000. Agency. Journal of Linguistic Anthropology, Vol. 9 (1-2): $12-15$

Ahearn, M. L., 2001. Language and agency. Annual Review of Anthropology, Vol. 30(1): 109-137

Al-Sharmani, M., 2003. Livelihood and identity construction of Somali refugees in Cairo. Forced migration and refugee studies. Working paper No.2.

Alkire, S., 2002. Dimensions of human development. World Development, Vol. 30(2): 181-205

Alkire, S., 2005. Needs and capabilities. In: The philosophy of need. Reader, S., (Ed) Cambridge University Press, Cambridge, 2002, pp. 229-251

Alvarez, M., 2009. Acting intentionally and acting for a reason. Inquiry: an interdisciplinary journal of Philosophy, Vol. 52(3): 293-305

Asad, T., 2000. Agency and pain: an exploration. An interdisciplinary journal of culture and religion, Vol. 1(1): 29-60 
Awumbila, M, Teye, K. J., and Yaro, A. J., 2017. Social networks, migration trajectories and livelihood strategies of migrant domestic and construction workers in Accra, Ghana. Journal of Asian and African Studies, Vol. 52(7): 982-996

Balyejjusa, M. S., 2015. Meanings and understandings of wellbeing: an exploration of Somali refugees' conceptions of human wellbeing. Africanus Journal of Development Studies, Vol. 45(2): 72-90

Balyejjusa, M. S., 2017. The wellbeing of Somali refugees in Kampala: Perceived satisfaction of their human needs. Journal of Science and Sustainable Development, Vol. 6 (1): 94-111

Beaman, A. L., 2012. Social networks and the dynamics of labour market outcomes: evidence from refugees resettled in the US. Review of Economic Studies, Vol. 79(1): 128-161

Berry, W. J., 2006. Contexts of acculturation. In: The Cambridge handbook of acculturation psychology, Sam, L. D., and Berry, W. J., (Eds.). Cambridge University Press, Cambridge, 2006, pp. 27-42

Black, R., 1994. Livelihoods under stress: A case study of Refugees vulnerability in Greece. Journal of Refugee Studies, Vol. 7(4): 360-377

Boeije, H., 2010. Analysis in Qualitative research. London: Sage publications.

Braun, V., and Clarke, V., 2013. Successful qualitative research: A practical guide for beginners. London: Sage publications

Caserta, A. T, Punamaki, R., and Pirttila-Backman., 2017. The buffering role of social support on the psychosocial wellbeing of orphans in Rwanda. Social Development, Vol. 26 (2): 402-422

Cheah, H. W., Karamehic-Muratovic, A., Matsuo, H., and Poljarevic, A., 2010. The influence of personal predispositions on Bosnian refugees' resettlement process. The International Journal of Interdisciplinary Social Sciences, Vol. 5(7): 37-48

Clark, R. C., 2007. Understanding vulnerability: From categories to experiences of young Congolese people in Uganda. Children and Society, Vol. 21(4): 284-296

Connor, P., 2010. Explaining the refugee gap: economic outcomes of refugees versus other Immigrants. Journal of Refugee Studies, Vol. 23(3): 377-397

Dean, H., 2010. Understanding human need: social issues, policy and practice. Bristol: Polity press

Desjarlais, R., 1997. Shelter blues: sanity and selfhood among the homeless. Philadelphia: University of Pennsylvania press.

Divakalala, C., 2008. Contested notions of wellbeing: peoples and donors' perceptions in Batticaloa, Sri Lanka. Masters thesis, The Netherlands, Institute of Social Studies.

Doyal, L., and Gough, I., 1991. A theory of human need. London: Macmillan.

Duranti, A., 2004. Agency in Language. In: A companion to linguistic Anthropology. A Duranti (ed) Blackwell publishing, Oxford, 2004, pp. 451-473

Essed, P., Frerks, G., and Schrijvers, J., 2005. Introduction: Refugees, Agency and social Transformation. In: Refugees and the transformation of Societies: Agency, 
Policies, Ethics and Politics. Essed, P., Frerks, G., and Schrijvers, J., (eds.) Berghahn Books, Oxford, 2005, pp. 1-16

Faas, J. A., Jones, C. E., Tobin, A. G., Whiteford, M. L., and Murphy, D. A., 2015. Critical aspects of social networks in settlement setting. Development in Practice, Vol. 25(2): 221-233

Gateley, E. D., 2015. A policy of vulnerability or agency? Refugee young people's opportunities in accessing further and higher education in the UK. Compare: A Journal of Comparative and International Education, Vol. 45(1): 26-46

Gasper, D., 2005. Subjective and objective well-being in relation to economic inputs: puzzles and responses. Review of Social Economy, LXIII (2): 177-206

Gibson, A. M., 2001. Immigrant adaptation and patterns of acculturation. Human Development, Vol. 44(1): 19-23

Giddens, A., 1984. The constitution of society: outline of the theory of structuration. Los Angeles: University of California press

Giddens, A., 1993. New rules of sociological method: A positive critique of interpretative Sociologies. Second revised edition. Cambridge: Polity press

Glesne, C., 2011. Becoming Qualitative researchers: and introduction. New York: Pearson

Gough, I., 2000. Global Capital, Human Needs and Social policies. New York: Palgrave.

Gough, I., 2003. Lists and thresholds: comparing the Doyal-Gough theory of human need with Nussbaum's capabilities approach. WeD working paper 01. University of Bath.

Government of Uganda., 1995. Constitution of the republic of Uganda, 1995. Kampala: Government of Uganda

Government of Uganda., 2006. The refugee Act 2006. Kampala: Government of Uganda.

Government of Uganda., 2010. The refugees regulation, Kampala: Government of Uganda.

Green, J., and Hart, L., 1999. The impact of context on data. In: Developing focus group research: politics, theory and practice, Barbour, S.R., and Kitzinger, J., (Eds.) Sage publications, London, 1999, pp. 21-35

Heaney, A. C., and Israel, A. B., 2008. Social networks and social support. In: Health behaviour and health education: theory, research and practice. Glanz, K., Rimer, K. B., and Viswanath, K., (Eds) Jossey-Bass, San Francisco California, 2008, pp. 185-209

Hennink, M., Hutter, I., and Bailey, A., 2011. Qualitative research methods. London: Sage Publications

Jinnah, Z., 2010. Making a home in a hostile land: understanding Somali identity, integration, livelihood and risks in Johannesburg. Journal of Sociology and Social Anthropology, Vol. 1(1-2): 91-99 
Karp, I., 1986. Agency and social theory: a review of Anthony Giddens. American Ethnologist, Vol. 13(1): 131-137

Kivisto, P., and Faist, T., 2010. Beyond a border: The causes and consequences of contemporary Immigration. Washington DC: Pine Forge Press

Lalu, P., 2000. The grammar of domination and the subjection of agency: Colonial texts and modes of evidence. History and theory, Vol. 39(4): 45-68

Landau, B. L., and Freemantle, I., 2010. Tactical cosmopolitanism and idioms of belonging: insertion and self-exclusion in Johannesburg. Journal of Ethnic and Migration Studies, Vol.36(3): 375-390

Langellier, M. K., 2008. Negotiating Somali identity in Maine. In: Applied communication in organizational and international contexts. Fine, C.E., and Schwandt, B., (Eds) Rohrin Universitatsverlag. Ingbert, 2008, pp. 97-106

Langellier, M. K., 2010. Performing Somali identity in the diaspora. Cultural Studies, Vol. 24 (1): 66-94

Lewis, M.I., 2008. Understanding Somalia and Somaliland. New York: Columbia University press

Lim, C., and Putnam, D. R., 2010. Religion, social networks, and life satisfaction. American Sociological Review, Vol. 75(6): 914-933

Madhok, S., 2013. Rethinking agency: developmentalism, gender and rights. New Delhi: Routledge

Malik, A. A., Mohr, E., Irvin-Erickson, Y., Landau, B. L., Kihato, W. C., and Edwards, B., 2017. Mapping the structure of well-being and social networks of refugees: a case study of Afghan refugees in Peshawar, Pakistan. Research Report, Center on International Development and Governance, Urban Institute

Marshall, C., and Rossman, B. G., 2006. Designing qualitative research. London: Sage publications

Mauss, M., 1970. The gift: forms and functions of exchange in archaic societies. London: Cohen and West Ltd

Mayr, E., 2011. Understanding human agency. Oxford: Oxford university press.

McGuire, M.J., 2012. Side-effect actions, acting for a reason, and acting intentionally. Philosophical Explorations, 15(3): 317-333

Morgan, L.D., 1997. Focus groups as qualitative research. London: Sage publications.

Mugalu, M., 2011. Post 7/11: Somalis praise Ugandans' friendliness. The Observer [Online] Available from: http://www.observer.ug/index.php?option=com_content\&view=article\&id=14220 $\% 3$ Apost-711-somalis-praise-ugandansfriendliness \&catid $=57 \% 3$ Afeature \&Itemid $=69$ [Accessed 10 July 2013]

O'Higgins, A., 2012. Vulnerability and agency: beyond an irreconcilable dichotomy for social service providers working with young Refugees in the UK. New Directions for Child and Adolescent Development, Vol. 2012(136): 79-91 
Omata, N., 2012. Refugee livelihoods and the private sector: Ugandan case study. Refugee Studies Centre, University of Oxford, Working Paper series No. 86

Ortner, S. B., 2001. Specifying agency: the Comarroffs and their critics. Interventions: International Journal of Postcolonial Studies, Vol. 3(1): 76-84

Ortner, S.B., 2006. Anthropology and social theory: Culture, Power, and the Acting Subject. London: Duke University press

Otiso, M.K., 2006. Culture and customs of Uganda. London: Greenwood press.

Pinquart, M., and Sorensen, S., 2000. Influence of socioeconomic status, social networks and competence on subjective well-being in later life: a meta-analysis. Psychology and Aging, Vol. 15(2): 187-224

Potocky-Tripodi, M., 2003. Refugee economic adaptation: theory, evidence, and implications for policy and practice. Journal of Social Service Research, Vol. 30(1): 63-91

Samatar, S. S., 1993. The society and its environment. In: Somalia: A country Study. Metz, C. H., (Ed). Federal research Division, Washington D.C, 1993, pp. 55-117

Sadouni, S., 2009. 'God is not unemployed': journeys of Somali refugees in Johannesburg. African studies, Vol. 68(2): 235-249

Schatz, J. E., 2009. Reframing vulnerability: Mozambican Refugees' access to statefunded pensions in rural South Africa. Journal of Cross Cultural Gerontology, Vol. 24(3): 241-258

Sen, A., 1985. Well-being, agency and freedom: the Dewey lectures 1984. Journal of Philosophy, Vol. 82(4): 169-221

Sen, A., 1999. Development as freedom. New York: Anchor books.

Sen, A., 2008. Capability and well-being. In: The philosophy of economics: An anthology. Hausman, M. D., (Ed.) Cambridge University Press: Cambridge, 2008, pp. $270-293$

Sewell, H. W., 1992. A theory of structure: duality, agency, and transformation. American Journal of Sociology, Vol. 98(1): 1-29

Stewart, W. D., and Shamdasani, N. P., 1990. Focus groups: theory and practice. London: Sage publications

Strauss, A., and Corbin, J., 1998. Basics of qualitative research: Techniques and procedures for developing grounded theory. London: Sage publications

Takeda, J., 2000. Psychological and economic adaptation of Iraqi adult male refugees: implications for Social Work practice. Journal of Social Service Research, Vol. 26(3): 1-21

Uganda Bureau of Statistics., 2017. 2017 Statistical Abstract. [Online] Available From https://www.ubos.org/wpcontent/uploads/publications/03_20182017_Statistical_Abstract.pdf [Accessed 4 July 2018]

Wertsch, V. J, Tulviste, P., and Hagstrom, F., 1993. Sociocultural approach to agency. In: Contexts for learning: sociocultural dynamics in children's development. 
Forman, A. E., Minick,N., and Stone, C. A., (Eds). Oxford University press, New York, 1993, pp. 336-356

Wright, K., 2012. International migration, development and human wellbeing. New York: Palgrave Macmillan

\section{Author Biography}

Moses Balyejjusa Senkosi (PhD) is a lecturer of Social Work at Uganda Christian University. His work broadly focuses on Human Wellbeing, Human Needs and Human Migration. Moses holds a doctorate degree in Social Change from the University of Melbourne. 